\title{
Commentary: Takotsubo Cardiomyopathy-Acute Cardiac Dysfunction Associated With Neurological and Psychiatric Disorders
}

\author{
Josef Finsterer ${ }^{*}$ and Claudia Stöllberger \\ Krankenanstalt Rudolfstiftung, Messerli Institute, Vienna, Austria
}

Keywords: Takotsubo, stunned myocardium, peripheral nervous system, heart failure, central nervous system

\section{A Commentary on}

Takotsubo Cardiomyopathy-Acute Cardiac Dysfunction Associated With Neurological and Psychiatric Disorders

\section{OPEN ACCESS}

Edited by:

Bernhard Schaller,

University of Zurich, Switzerland

Reviewed by:

Pietro Enea Lazzerini,

University of Siena, Italy

*Correspondence:

Josef Finsterer

fifigs1@yahoo.de

Specialty section:

This article was submitted to Autonomic Neuroscience,

a section of the journal

Frontiers in Neurology

Received: 22 September 2019 Accepted: 15 October 2019 Published: 31 October 2019

Citation:

Finsterer J and Stöllberger C (2019)

Commentary: Takotsubo

Cardiomyopathy-Acute Cardiac

Dysfunction Associated With

Neurological and Psychiatric

Disorders. Front. Neurol. 10:1163.

doi: 10.3389/fneur.2019.01163 by Buchmann, S. J., Lehmann, D., and Stevens, C. E. (2019). Front. Neurol. 10:917. doi: 10.3389/fneur.2019.00917

With interest we read the review article by Buchmann et al. about Takotsubo cardiomyopathy (TTC), an acute reversible heart failure syndrome, triggered by neurological or psychiatric disorders (1). The authors concluded that the international expert consensus document on TTC, published by Ghadri et al. (2), "should be used in the daily clinical routine to provide excellent patient care" (1). We have the following comments and concerns.

We do not agree with the notion that only disorders of the central nervous system (CNS) cause TTC (1). Also disorders of the peripheral nervous system (PNS) have been shown to trigger TTC [Table 1; (3)] although these data are mainly provided by single case reports. For example, it is well-established that patients with myasthenia gravis who experience an acute myasthenic or cholinergic crisis leading to respiratory distress, can develop TTC (3). A myasthenic or cholinergic crisis may evoke fear of dying from respiratory insufficiency and the resulting catecholamine storm is believed to trigger TTC. A combined CNS/PNS disorder which has been reported to trigger TTC is amyotrophic lateral sclerosis (ALS) (4). ALS is characterized by rapidly progressive muscle weakness including bulbar and axial muscles, either already at onset of the disease or during the further course, and clinically manifesting as respiratory insufficiency or swallowing dysfunction. Furthermore, these patients may be confronted with the situation to suffocate, which may trigger the catecholamine storm (4). A further PNS disease reported to be involved in the development of TTC, is autonomic neuropathy in patients with diabetes (5). TTC has been also reported in hereditary motor and sensory neuropathy (HMSN) (6).

We also do not agree that TTC may be triggered only by the CNS disorders subarachnoid bleeding, epilepsy, intracerebral bleeding, ischemic stroke, meningitis/encephalitis, migraine, or traumatic brain injury (1). CNS disorders other than those mentioned in the review being associated with TTC include Parkinsonism, brain tumors (7), dementia (8), multiple sclerosis, serotonin syndrome, and others (Table 1). In a review about TTC and neurological disorders these 
TABLE 1 | Neurological and psychiatric conditions triggering TTC.

\begin{tabular}{|c|c|c|}
\hline Neurological/psychiatric triggers of TTC & Frequency & Level of evidence \\
\hline \multicolumn{3}{|l|}{ NEUROLOGICAL TRIGGERS } \\
\hline Subarachnoid bleeding & Frequent & Studies \\
\hline Seizures & Frequent & Studies \\
\hline Intra-cerebral bleeding & Frequent & Studies \\
\hline Ischemic stroke & Frequent & Studies \\
\hline Meningitis/encephalitis & Rare & Studies \\
\hline Transient global amnesia & Rare & Studies \\
\hline Migraine & Rare & Studies \\
\hline Traumatic brain injury & Rare & Case reports \\
\hline Parkinsonism & Rare & Case reports \\
\hline Brain tumor & Rare & Case reports \\
\hline Dementia & Rare & Case reports \\
\hline Multiple sclerosis & Rare & Case reports \\
\hline Serotonin syndrome & Rare & Case reports \\
\hline Aterio-venous fistula & Rare & Case report \\
\hline Cyclic vomiting syndrome & Rare & Case report \\
\hline Cerebral hypoxia & Rare & Case report \\
\hline Acute myelitis & Rare & Case report \\
\hline Hydrocephalus & Rare & Case reports \\
\hline Chiari-I malformation & Rare & Case report \\
\hline PRES & Rare & Case reports \\
\hline \multicolumn{3}{|l|}{ PSYCHIATRIC TRIGGERS } \\
\hline Affection disorder & Frequent & Studies \\
\hline Anxiety disorder & Frequent & Studies \\
\hline Psychosis & Rare & Case report \\
\hline Substance abuse & Rare & Case report \\
\hline Attention deficit hyperactivity disorder & Rare & Case report \\
\hline Anorexia nervosa & Rare & Case report \\
\hline
\end{tabular}

PRES, posterior reversible encephalopathy syndrome. other CNS conditions need to be discussed. However, for several of these CNS conditions not included in the review by Buchmann et al. (1) data mainly derived from single case reports (9).

Concerning psychiatric disease as a trigger of TTC, not only affective disorders and anxiety disorders may trigger TTC but also in psychosis and substance abuse, particularly opiate withdrawal (10). Whether truly all TTC patients have high illness-related anxiety levels remains speculative.

The review lacks a discussion about echocardiography and cardiac MRI as a tool to diagnose TTC. Echocardiography is the imaging method of choice for detecting TTC in the acute situation. If the patient is in a stable condition and in case of uncertainty, ventriculography, or cardiac MRI may be useful alternatives, if available and applicable.

The review also does not extensively discuss the subtypes of TTC (apical, midventricular, basal, lateral, and global). Particularly, there is no discussion about the frequency of these subtypes among neurologically ill patients in relation to the triggering neurological disease.

Concerning the diagnostic criteria, it is crucial that coronary heart disease is excluded by coronary angiography or by CTangiography of the coronary vessels.

Overall, the review by Buchmann et al. (1) has a number of shortcomings. The review does not mention PNS disorders as triggers of TTC. Also a number of CNS disorders which can trigger TTC has not been mentioned. Cardiac MRI is not discussed as diagnostic tool and the different subtypes of TTC were not considered.

\section{AUTHOR CONTRIBUTIONS}

JF: design, literature search, discussion, first draft, and critical comments. CS: discussion and critical comments.

myocardium in Pediatrics. A case report. Rev Esp Anestesiol Reanim. (2015) 62:472-6. doi: 10.1016/j.redar.2014.10.010

8. Zuin M, Dal Santo P, Picariello C, Conte L, Zuliani G, D’Elia K, et al. Takotsubo cardiomyopathy in an elderly woman with Alzheimer's disease: a rare association. case report and mini-review of the literature. J Am Geriatr Soc. (2016) 64:916-7. doi: 10.1111/jgs.14071

9. Morris NA, Chatterjee A, Adejumo OL, Chen M, Merkler AE, Murthy $\mathrm{SB}$, et al. The risk of takotsubo cardiomyopathy in acute neurological disease. Neurocrit Care. (2019) 30:171-6. doi: 10.1007/s12028-01 8-0591-z

10. Nayeri A, Rafla-Yuan E, Krishnan S, Ziaeian B, Cadeiras M, McPherson JA, et al. Psychiatric illness in takotsubo (Stress) cardiomyopathy: a review. Psychosomatics. (2018) 59:220-6. doi: 10.1016/j.psym.2018. 01.011

Conflict of Interest: The authors declare that the research was conducted in the absence of any commercial or financial relationships that could be construed as a potential conflict of interest.

Copyright () 2019 Finsterer and Stöllberger. This is an open-access article distributed under the terms of the Creative Commons Attribution License (CC BY). The use, distribution or reproduction in other forums is permitted, provided the original author(s) and the copyright owner(s) are credited and that the original publication in this journal is cited, in accordance with accepted academic practice. No use, distribution or reproduction is permitted which does not comply with these terms. 